\title{
Mediating Role of Perceived Value on the Relationship Among Perceived Risks, Perceived Quality, and Purchase Intention of Private Label Brands
}

Meenu Mathur, PhD

Institute of Management Studies, Sage University, Indore, Madhya Pradesh, India. (iD https://orcid.org/0000-0002-3845-9162

Sanjeevni Gangwani, $\mathrm{PhD}$

Department of Graduate Studies and Scientific Research, Princess Nourah bint Abdulrahman University, Riyadh, Saudi Arabia

(iD) https://orcid.org/0000-0002-0918-7268

Contact: mathur.meenu1@gmail.com

\begin{abstract}
In the current competitive retail market, retailers constantly strive to deliver products to consumers at a better value. Consumers are becoming more price sensitive but still seeking quality products. A retailer can establish value with a brand. Consequently, retailers are introducing their own private label brands (PLBs), which also differentiate their products from competitors. The role of perceived value in the purchase behavior of PLBs and its relationship with quality and various risk dimensions has received scant consideration in the retailing literature. Our study suggests perceived value is a mediating part in associations amid perceived quality, perceived risks, and purchase intention of PLBs. A structural equation modeling approach was adopted to test the proposed hypotheses with a convenience sample of 458 consumers of retail department stores obtained via a cross-sectional survey. The results demonstrate that the role of perceived value is vital in strengthening the association of consumer-perceived quality and purchase intention of PLBs as well as minimizing the consumer's risks as they intend to buy PLBs. Overall, the study contributes to the emerging retail and consumer behavior literature regarding the role of perceived value in purchase intention of PLBs.
\end{abstract}

Keywords: consumer behavior, private label brands, retail, purchase behavior, perceived risks, perceived quality, perceived value

Date Submitted: February 2, 2021 | Date Published: September 24, 2021

\section{Recommended Citation}

Mathur, M., \& Gangwani, S. (2021). Mediating role of perceived value on the relationship among perceived risks, perceived quality, and purchase intention of private label brands. International Journal of Applied Management and Technology, 20, 71-87. https://doi.org/10.5590/IJAMT.2021.20.1.04 


\section{Introduction}

In the prevailing competitive retail environment, numerous brands strive to deliver better customer value as their core branding and marketing strategies (Hansen et al., 2008). The consumer-perceived value has a favorable effect on market share (Swait \& Sweeney, 2000). Therefore, retailers need to appreciate the consumer expectations regarding their value propositions. As per Baltas and Argouslidis (2007), over time, the enhanced quality of PLBs with their reasonable prices is one of the major factors for the mounting reception of PLBs among consumers. Consequently, consumers perceive PLBs as "value" products (Thanasuta, 2015).

Meanwhile, retailers increasingly witness rapid changes in the consumers' needs and preferences, with evolving technology disruptions enabling a shift in the way retailers can create consumer value. Presently, a retailer can establish value by a brand and its consumers, and, thus, consumers' perceptions and expectations about their desired value are crucial and ought to be considered as one of the foundations of retail management. This caused many brands to develop a better understanding of the determinants of customer value to craft a sustainable competitive advantage (Lapierre, 2000). There is a general belief that consumers' willingness to buy the product will increase provided a product delivers the desired value. Foremost, the question is whether the perceived value of a retailer's product plays a central role in PLB buying decisions. It is likely that the determinants influencing purchase intention of PLBs vary among consumers with high perceived value as compared to those consumers with low perceived value. In addition, minimizing perceived risk adds to higher perceived customer value (Broydrick, 1998) where the extent of perceived risk is a consequence of the apparent outcome of purchase. Woodall (2003) also identified perceived risk as a determining factor in the consumers' perception of the value, while Bhukya and Singh (2015) accentuate that consumer-perceived risk negatively influences purchase behavior. Multidimensional in nature, the perceived risk by consumers includes functional risk (uncertainty about product performance), financial risk (expected loss of money due to poor product purchase decision/quality), and social risk (expected loss of image or status due to product purchase).

To understand the PLB consumer behavior and assess the possible risk involved, many research studies have considered overall perceived risk as a single construct (Diallo, 2012; Wu et al., 2011), but few have examined perceived risk dimensions in the context of PLBs (Manikandan, 2020; Bhukya \& Singh (2015); Liljander et al., 2009). Moreover, none of the studies have examined the mediating effect of perceived value between perceived risk dimensions and purchase intention of PLBs. Furthermore, in the literature, the concept of consumer-perceived value is stated as a dynamic and time-dependent variable. As stated by Woodall (2003), "not only does each of us value the same things differently, we individually value different things, and at different times in different ways" (p. 4). Thus, a longitudinal perspective on consumer-perceived value calls for more consideration and demonstrates a research gap among value perceptions of post-purchases (Graf \& Maas, 2008), which is referred to as consumer-perceived value in the literature. Consequently, the decisive factors for value assessment may vary at different times (Oliver, 2010), which suggests that future perceptions are persuaded by prior purchase experiences (Sweeney \& Soutar, 2001), an appealing area of research. The focus of our current study is on modern Indian retailing and intends to develop a model to investigate the purchase intention of PLBs; only specific antecedents, that is, three perceptual constructs, are considered. The model postulates that consumer-perceived value mediates the affiliations and links perceived financial, functional, and social risks with perceived quality to purchase intention.

Our study addresses the previously mentioned literature gaps. The purpose of this study is twofold: (1) to inspect the effect of perceived risk dimensions, including functional risk, financial risks, and social risks with quality on perceived value and purchase behavior; and (2) to make considerable contributions to the literature of social sciences and consumer behavior, by investigating the mediation effects of perceived value with the affirmed factors and purchase intention of consumers. Our study suggests perceived value is a mediating part 
in association with perceived quality, perceived risks, and purchase intention of PLBs. Consequently, we address the following specific research questions, which also define the scope of the study:

- Does the consumers' perceived value influence the consumers' purchase intention of PLBs?

- Does the consumers' perceived quality influence the consumers' purchase intention of PLBs?

- Do the consumers' perceived risks (functional risk, financial risk, social risk) influence the consumers' purchase intention of PLBs?

- Does the consumers' perceived quality influence the consumers' perceived value of PLBs?

- Do the consumers' perceived risks (functional, financial, and social) influence the consumers' perceived value of PLBs?

- Does perceived value mediate the relationship between perceived product quality and the consumers' purchase intention of PLBs?

- Does the consumers' perceived value mediate the relationship between perceived risks (functional, financial, social) and the consumers' purchase intention of PLBs?

We first discuss relevant literature, develop the hypotheses, and present methodology and research questions; then, we illustrate our analysis of the data. Later, we present our findings and state recommendations. Finally, we present implications of the study to practice, limitations, and possible avenues of further research.

\section{Literature Review and Hypothesis Development}

Since the emergence of PLBs as a competitor to national brands, path-breaking research has been undertaken on the purchase behavior of PLB consumers. The likelihood of consumers buying a product in the future is referred to as purchase intention (Diallo, 2012). It encompasses the decision process a consumer undergoes to satisfy an impending need. Therefore, an increase in purchase intention enhances the likelihood of product purchase (Schiffman \& Kanuk, 2011).

To understand consumer behavior in the decision-making process, the literature identifies purchase intention as a key factor (Chakravarti \& Janiszewski, 2003). Muruganantham and Priyadharshini (2017), while reviewing PLB literature, proposed a holistic framework on the PLB purchase behavior based on the most repeatedly studied factors as store proneness determinants. The consumer decision-making process for PLB purchase involves mainly price and value consciousness, which occurs from the belief of value for money toward products. Further, consumers' product assessment is made on risk factors, the functionality of the products, and the assessment that the products are financially and socially risk free, assuming that consumers are supposedly smart shoppers. Indian consumers perceive PLBs as quality brands that deliver excellent value though priced lower compared to national brands.

\section{Perceived Value}

Perceived value is the major factor in creating a positive perception of the PLB and strengthens the linkages between the consumer and the brand (Kara et al., 2009). Perceived value is formed as an outcome of the brand's purchase and consumption experiences of the consumers (Cronin et al., 2000). Perceived value for money denotes the consumers' evaluation of a product with respect to its price (Wu et al., 2011). Relative to its price, perceived value of a brand entails a view of brand quality, perhaps not in its totality (Richardson et al., 1996). Sirohi et al. (1998) also called this value-for-money evaluation "what you get for what you pay." In equity theory terminology, perceived value is explained as "that which is believed to be fair, right or deserved in relation with the perceived cost of the offering, while taking into consideration appropriate competitor choices" (Zeithaml, 1988, p. 13). Perceived value is revealed to be one of the antecedents of purchase intentions in the context of a retail store (Sirohi et al., 1998). The consumer-perceived value is debatably the most decisive determinant of purchase intention (Hsin Chang \& Wang, 2011). 
There are numerous studies adjoining this interesting value creation phenomenon among academics and marketing practitioners, which mainly highlight linkages between consumer's perceived value and loyalty towards a brand (Yang \& Wang, 2010), decision-making process (Beneke et al., 2013; Richardson et al., 1996), and purchase intention (Dodds et al., 1991).

Beneke and Carter (2015) investigated the major drivers of the PLBs' perceived value, and the results revealed that consumers notice value via price, risk, and quality cues. While Yee and San (2011) revealed direct linkages between the consumers' perceived value and their purchase decisions and explained that the greater the consumer-perceived value of a product, the greater their intention to purchase that specific product. A "value for money" is a "worth," which describes the schema of PLBs in the memory of a consumer (NenyczThiel \& Romaniuk, 2012). Thus, consumer perceptions that PLBs are value-for-money offerings are critical for attracting customers towards PLBs. Ascertaining a value perception is significant in the buying decisions, and perceived value positively impacts willingness to buy PLB products (Beneke et al., 2013). Addressing these empirical confirmations, we framed the following null hypothesis:

H1: The consumers' perceived value influences the consumers' purchase intention of PLBs.

\section{Perceived Quality}

Aaker (1991) observed perceived quality as a vital constituent of the overall brand value and, thus, defined it as "the intangible and overall consumer sentiment regarding a particular brand. It may be described as the result of features inherent in the product itself and additionally emphasized by the label, such as performance or reliability" (p. 3). Zeithaml (1988) defined "perceived quality as the consumer's opinion about the product's overall excellence and superiority" (p. 3). Quality lies at the center of the rivalry among PLBs and national brands, both with respect to the consumers' wish for quality and the retailer's capability to deliver it (Hoch, 1996). This outlook aligns with the research by Veloutsou et al. (2004), who also reiterated that quality is an evenly imperative alternative decisive factor for consumers when buying both PLBs and national brands. While applying brand personality on PLBs, Glynn and Widjaja (2015) showed that "all private label personality dimensions influenced the private label quality measure with the confidence and sincerity dimensions having the greatest impact” (p. 362). Huei Cham et al. (2018) showed that perceived quality of apparel positively relates with an individual's clothing interest wherein price consciousness moderates the association with clothing interest and purchase intention.

The literature reveals significantly positive links between perceived quality and PLB purchase intentions. Perceived quality and value of PLBs directly affect the purchase intention that consumers have for PLBs (Liljander et al., 2009). More recently, Konuk (2018) and Yan et al. (2019) also confirmed the same for PLBs. The results of such studies conclude that the higher the strength or the more favorable the consumer perception, the more likely PLBs would be purchased, and further patronage toward the PLB would be developed.

H2: The consumers' perceived quality influences the consumers' purchase intention of PLBs.

H2a: The consumers' perceived value mediates the relationship between perceived product quality and the consumers' purchase intention of PLBs.

H3: The consumers' perceived quality influences the consumers' perceived value of PLBs.

\section{Perceived Risk}

Risk is the consumers' perceptions of ambiguity and unpleasant penalties of engaging in any activities (Dowling \& Staelin, 1994); however, the most general definition is “consumer's subjective expectations of a loss" (Sweeney et al., 1999). According to Bauer (1960), "Perceived risk has two parts: uncertainty (the 
likelihood of unfavorable outcomes) and consequences (the importance of a loss)." In the context of consumer behavior, the term "perceived risk," according to Stone and Grønhaug (1993), explains "consumer's perceptions of uncertainties and unfavorable consequences related to the buying of products or services" (p. 40). While making a purchase decision, consumers seem to notice not only instant benefits but also lasting purchase outcomes (Sweeney et al., 1999). The literature shows perceived risk dimensions considered most frequently are, overall, financial and performance risks (Grewal et al., 1998; Sweeney et al., 1999; Agarwal \& Teas, 2001) because they seem to be low on product specifics as compared with other dimensions.

Those products that are noticeable and correspond to the self-image of a consumer, such as clothes and accompanying fashion accessories, for instance, constitute "social risk" (Liljander et al., 2009; Stone \& Grønhaug, K., 1993) or self-image risk (Liljander et al., 2009). This is predominantly important as clothing is associated with the social identity of consumers and is the means to express self-identity. In reference to clothes purchasing, the significance of social risk is also well cited by Jacoby and Kaplan (1972). Additionally, social risk might dissuade a consumer from making a purchase, especially in a situation when the consumer faces disapproval from relatives or friends who play a considerable role in discouraging consumers from making purchase decisions.

Bhukya and Singh (2015) found that perceived functional risk, financial risk, and psychological (social) risk have a direct negative effect on consumers' purchase intention toward PLBs. Alic et al. (2013) explored the direct impact of perceived risk that consumers experience while making decisions about buying PLBs and the effects of select dimensions of perceived risk on buying PLBs. This perception negatively impacts their perception of the quality of the PLBs they may want to buy. Similarly, physical risk (in terms of feeling secure when using a PLB product) also has significant indirect effects on the quality perceptions of PLBs.

The study by Alic et al. (2013) also implied that the risk is with respect to possible financial loss. The likelihood that the offerings will not provide the probable value with respect to the paid price significantly determines overall perceived risk, and, therefore, it indirectly determines the perceived quality of the product under the private label, regardless of the observed product category (milk is a typical conventional product).

Our study summarized these perceptions of PLBs and framed the following hypotheses:

H4: The consumers' perceived functional risk influences the consumers' perceived value of PLBs.

H5: The consumers' perceived functional risk influences the consumers' purchase intention of PLBs.

H6: The consumers' perceived financial risk influences the consumers' purchase intention of PLBs.

H7: The consumers' perceived financial risk influences the consumers' perceived value of PLBs.

H8: The consumers' perceived social risk influences the consumers' purchase intention of PLBs.

H9: The consumers' perceived social risk influences the consumers' perceived value of PLBs.

It's imperative to appreciate that the two important drivers that impact the private label's perceived value are risk and quality (Beneke et al., 2013; Dodds et al., 1991). In particular, Beneke et al. (2013) identified that consumer-perceived value mediates the links between these antecedents and purchase intentions of a brand.

This concludes the framing of the following hypotheses:

H3a: The consumers' perceived value mediates the relationship between perceived functional risk and the consumers' purchase intention of PLBs.

H3b: The consumers' perceived value mediates the relationship between perceived financial risk and the consumers' purchase intention of PLBs. 
H3c: The consumers' perceived value mediates the relationship between perceived social risk and the consumers' purchase intention of PLBs.

\section{Methodology and Research Questions}

\section{Sampling and Data Collection}

Using a quantitative research method, we designed a cross-sectional consumer survey questionnaire after a detailed review of the suitable literature. A non-probability convenience sampling technique was administered, and primary data were collected from the various organized retail department stores in Indore city, which is in the state of Madhya Pradesh in central India. The respondents were clearly briefed regarding the aim of the study. Participation was voluntary, and anonymity was assured. Participants willingly answered questions regarding their last shopping experience at retail department stores and, after the researchers checked their awareness about apparel PLBs of the store, they were measured as the sample. Appropriate examples of PLBs were listed in the questionnaire as a reference for respondents. The dataset of the study includes 458 valid responses (for sample characteristics, refer to Table 1).

Table 1. Sample Characteristics

\begin{tabular}{|c|c|c|}
\hline Categories & $\begin{array}{l}\text { No. of } \\
\text { Participants }\end{array}$ & $\begin{array}{l}\text { Percentage in the } \\
\text { Sample (\%) }\end{array}$ \\
\hline \multicolumn{3}{|l|}{ Gender } \\
\hline Male & 237 & 51.7 \\
\hline Female & 221 & 48.3 \\
\hline \multicolumn{3}{|l|}{ Marital status } \\
\hline Married & 229 & 50.0 \\
\hline Single & 229 & 50.0 \\
\hline \multicolumn{3}{|l|}{ Age (yr) } \\
\hline $18-24$ & 187 & 40.8 \\
\hline $25-34$ & 125 & $27 \cdot 3$ \\
\hline $35-44$ & 94 & 20.5 \\
\hline More than 45 & 52 & 11.3 \\
\hline \multicolumn{3}{|l|}{ Annual Family Income } \\
\hline Less than INR 199,999 & 62 & 13.5 \\
\hline INR 200,000-499,999 & 186 & 40.6 \\
\hline INR 500,000-999,999 & 147 & 32.1 \\
\hline More than INR $1,000,000$ & 63 & 13.8 \\
\hline \multicolumn{3}{|l|}{ Education } \\
\hline Undergraduate & 25 & $5 \cdot 5$ \\
\hline Graduate & 197 & 43.0 \\
\hline Postgraduate & 210 & 45.9 \\
\hline $\mathrm{PhD}$ & 26 & $5 \cdot 7$ \\
\hline
\end{tabular}




\section{Questionnaire}

The questionnaire included sections that measured the respondents' experiences of shopping apparel PLBs at retail department stores. It included questions on demographic variables; questions with respect to major constructs of the study were in the form of item statements. The major constructs of the study included the financial risk, functional risk, and social risk that consumers perceived while buying PLBs from a retail department store. In addition, the survey measured PLB-perceived quality, perceived value, and PLB purchase intention. Each construct had many items that were adapted from prior published work with wordings changed as required. The items were calculated on a 5-point Likert scale with responses ranging from "strongly agree" to "strongly disagree." Items measuring PLB-perceived quality were adapted from Vahie and Paswan (2006); the perceived social risk was measured on a scale from Dowling and Staelin (1994), Jacoby and Kaplan (1972), and used by Liljander et al. (2009). Financial risk was based on a scale by Stone and Grønhaug, K. (1993), Liljander et al. (2009), and Beneke et al. (2012). Functional risk measurement followed that established by Gonzalez et al. (2006) and Beneke et al. (2012). Item measurements for perceived value were made with items from Sweeney and Soutar (2001) and Dodds et al.(1991). Item measurements for PLB purchase intention were made with items from Diallo et al. (2013), Sweeney and Soutar (2001), Dodds et al. (1991), and Jin and Gu Suh (2005). A reliability test was performed for all the measured constructs of the study and the results confirmed an excellent level of internal consistency.

\section{Data Analysis}

\section{Confirmatory Factor Analysis (CFA)}

The measurement model of the study illustrated how much hypothetical latent constructs represented the observed variables of the study (Hair et al., 2013). Confirmatory factor analysis (CFA) indicated a good fit of the measurement model; it assessed all items to appraise uni-dimensionality and validity. The model had a chi-square value of $1.837(p<.000)$ at $80 \mathrm{df}$. The other model fit measures also indicated an acceptable fit; Normed Fit Index $(\mathrm{NFI})=.979$, Root Mean Square Error of Approximation (RMSEA) = .043, Comparative Fit Index $(\mathrm{CFI})=.990$, Tucker-Lewis index $(\mathrm{TLI})=.987$, Relative Fit Index $(\mathrm{RFI})=.973$, and Incremental Fit Index $(\mathrm{IFI})=.990$. Construct validity was checked by ensuring discriminant and convergent validity. All items load on their subsequent latent factor with significant $p$ value $=.000$ and, with loading more than .70 (Hair et al., 2013), were assessed as robust convergent validity of all constructs.

Table 2. Results of Confirmatory Factor Analysis

\begin{tabular}{|c|c|c|c|c|c|}
\hline Constructs & $\begin{array}{l}\text { Scale } \\
\text { Items }\end{array}$ & $\begin{array}{l}\text { Standardized } \\
\text { Loadings }\end{array}$ & Alpha & $\mathbf{C R}$ & $\overline{\text { AVE }}$ \\
\hline \multicolumn{2}{|c|}{ Perceived Value } & & .872 & .874 & .699 \\
\hline & V1 & .811 & & & \\
\hline & V2 & .886 & & & \\
\hline & $\mathrm{V}_{3}$ & .808 & & & \\
\hline \multicolumn{2}{|c|}{ Perceived Quality } & & .934 & .870 & .870 \\
\hline & Q1 & .933 & & & \\
\hline & Q2 & .940 & & & \\
\hline & Q3 & .861 & & & \\
\hline \multicolumn{2}{|c|}{ Perceived Social Risk } & & .963 & .963 & .898 \\
\hline & SR1 & 935. & & & \\
\hline & SR2 & 960 & & & \\
\hline & $\mathrm{SR}_{3}$ & 947 & & & \\
\hline
\end{tabular}




\begin{tabular}{|c|l|c|c|c|c|}
\hline Constructs & \multicolumn{1}{c|}{$\begin{array}{c}\text { Scale } \\
\text { Items }\end{array}$} & $\begin{array}{c}\text { Standardized } \\
\text { Loadings }\end{array}$ & Alpha & CR & AVE \\
\hline \multicolumn{2}{|l|}{ Perceived Financial Risk } & & .945 & .945 & .852 \\
\hline & FiR1 & .898 & & & \\
\hline & FiR2 & .928 & & & \\
\hline & FiR3 & .943 & & & \\
\hline \multicolumn{2}{|l|}{ Perceived Functional Risk } & & .887 & 895 & .742 \\
\hline & FR1 & .871 & & & \\
\hline & FR2 & .936 & & & \\
\hline & FR3 & .768 & & & \\
\hline
\end{tabular}

Note: $\mathrm{AVE}=$ average variance extracted; $\mathrm{CR}=$ composite reliability; $\mathrm{MSV}=$ maximum shared variance.

Fit statistics: $\chi 2(80 d f)=1.837,(p=.000), \mathrm{NFI}=.979, \mathrm{RMSEA}=.043, \mathrm{CFI}=.990, \mathrm{TLI}=.987, \mathrm{RFI}=.973$, and IFI $=.990$.

Table 3. CFA Model: Discriminant Validity and Correlation Between Constructs

\begin{tabular}{|l|c|c|c|c|c|l|c|}
\hline & MSV & MaxR (H) & Value & Quality & SoR & FinR & FuR \\
\hline Value & .540 & .882 & $\mathbf{. 8 3 6}^{a}$ & & & & \\
\hline Quality & .594 & .870 & $.735^{b}$ &. $\mathbf{9 3 3}$ & & & \\
\hline SoR & .473 & .965 & -.688 & -.765 & .948 & & \\
\hline FinR & .340 & .948 & -.542 & -.564 & .583 & $\mathbf{. 9 2 3}$ & \\
\hline FuR & .594 & .921 & -.706 & -.771 & 682 & .491 & $\mathbf{. 8 6 1}$ \\
\hline
\end{tabular}

Note: $\mathrm{MSV}=$ maximum shared variance; $\operatorname{MaxR}(\mathrm{H})=$ maximal reliability; Value = perceived value; Quality = perceived quality; SoR = perceived social risk; FinR = perceived financial risk;

$\mathrm{FuR}=$ perceived functional risk; PI = purchase intention.

${ }^{a}$ Square roots of AVE in bold.

${ }^{b}$ Correlation between constructs.

Thus, the measurement model of the study demonstrated robust psychometric properties with CR and AVE. CR values are .963 for perceived social risk, .895 for perceived functional risk, .946 for perceived financial risk, and .746 for perceived quality. All CR values upheld the suggested minimum value of .70 (Hair et al., 2013). In addition, the discriminant validity of all constructs was examined by validating that each latent construct is extracting greater variance from the respective indicator than it shares with all other constructs (refer to Table 2), and all values were found to be larger than the correlation estimates ascertaining discriminant validity (refer to Table 3).

After initial evaluation of the fitness-of-measurement model, the testing of the structural model was conducted with maximum likelihood estimate while observing the covariance matrix. The measurement model illustrated how much hypothetical latent constructs represent the observed variables (Hair et al., 2013) of the study. It was found that chi-square value (2.050) with $d f 137$ was significant $(p=.000)$ since it is inclined with the size of the sample (Kline, 2005). The other fit indices indicated a satisfactory fit of the structural model; $\mathrm{NFI}=.967, \mathrm{RMSEA}=.048, \mathrm{CFI}=.983, \mathrm{TLI}=.979$, and $\mathrm{IFI}=.983$. All these values indicate that the structural model is a good fit. For hypothesis testing, the parameter estimates were as stated in Table 4. As predicted, PLB perceived value was positively linked to PLB purchase intention (path estimate $=.205 ; p$ $=.000$ ), supporting hypothesis H1. This linkage implied that consumers who perceive the value of PLBs as 
favorable have favorable intention to purchase PLBs. Moreover, hypothesis H2, which indicated that PLB perceived quality positively influences PLB purchase intention, was also supported (path estimate $=.380 ; p$ value $=.000$ ). The results contradict an earlier study by Retnawati et al. (2018), which found quality perceptions of consumers were not significant to purchase intention of PLBs. They did find, however, that consumers' value of confidence can possibly enhance purchase intention of PLBs where consumers' conviction was measured with a belief that quality PLBs are needed and PLBs are comparable to national brand counterparts.

Table 4. Structural Model Parameter Estimates

\begin{tabular}{|c|c|c|c|}
\hline Hypothesized Relationships & Estimates & $\mathbf{C R}$ & $\begin{array}{l}\text { Sig. } \\
(p<.05)\end{array}$ \\
\hline H1: PLB Perceived Value $\longrightarrow$ PLB PI & .205 & 3.597 & .000 \\
\hline H2: PLB Perceived Quality $\longrightarrow$ PLB PI & .380 & $5 \cdot 948$ & .000 \\
\hline H3: PLB Perceived Functional Risk $\longrightarrow$ PLB PI & -.196 & -3.022 & .003 \\
\hline H4: PLB Perceived Financial Risk $\longrightarrow$ PLB PI & -.083 & -2.651 & .008 \\
\hline H5: PLB Perceived Social Risk $\longrightarrow$ PLB PI & -.186 & -3.949 & .000 \\
\hline H6: PLB Perceived Quality $\longrightarrow$ PLB PV & .292 & 4.144 & .003 \\
\hline H7: PLB Perceived Functional Risk $\longrightarrow$ PLB PV & -.321 & -4.419 & .000 \\
\hline H8: PLB Perceived Financial Risk $\longrightarrow$ PLB PV & -.094 & -2.638 & .008 \\
\hline H9: PLB Perceived Social Risk $\longrightarrow$ PLB PV & -.171 & -3.188 & .001 \\
\hline
\end{tabular}

Note: $\mathrm{PI}=$ purchase intention; $\mathrm{PV}=$ perceived value.

Consumers ought to be convinced with PLBs. A possible way to achieve conviction is to understand the risks involved as consumers intend to buy PLBs. The results illustrated that PLB perceived functional risk was negatively related to PLB purchase intention (path estimate $=-.196 ; p=.003$ ), supporting $\mathrm{H}_{3}$. This implied that when consumers perceived less functional risk in buying PLBs, their intention to purchase PLBs was enhanced. PLB-perceived financial risk was negatively related to PLB purchase intention (path estimate $=-.083 ; p=.008$ ), supporting $\mathrm{H}_{4}$. This implied that when consumers perceived less financial risk in buying PLBs, their intention to purchase PLBs increased. PLB-perceived social risk is negatively related to PLB purchase intention (path estimate $=-.186 ; p=.000$ ), supporting $\mathrm{H}_{5}$. This implied that when consumers perceived less social risk in buying PLBs, their intention to purchase PLBs was enhanced. PLB perceived quality was positively related to PLB perceived value (path estimate $=.292 ; p=.003$ ), supporting H6. This implied that when consumers perceived quality of PLBs as favorable, their intention to purchase PLBs was also favorable.

In addition, PLB perceived functional risk was negatively related to PLB perceived value (path estimate = -.321; $p=.000$ ), supporting $\mathrm{H} 7$. This implied that when consumers perceived less functional risk while buying PLBs, they perceived PLBs to be of increased value. PLB perceived financial risk was negatively related to PLB perceived value (path estimate $=-.094 ; p=.008$ ), supporting H8. This implied that when consumers perceived less financial risk in buying PLBs, they perceived PLBs to be of enhanced value. Moreover, PLB perceived social risk was negatively related to PLB perceived value (path estimate $=-.171 ; p=.001$ ), supporting H9. This implied that when consumers perceived less functional risk in buying PLBs, they perceived PLBs to be of improved value.

\section{Testing of Mediation Relationships}

The mediating effects of PLB perceived value were predicted using bootstrapping methods to find out the mediating relationships between the select independent variables (PLB perceived quality, PLB functional risk, 
PLB financial risk, and PLB social risk) and PLB purchase intention. As recommended by Preacher and Hayes (2008), the bootstrapping technique examines the indirect effects of unrelated variables. In addition, it gives precise results of confidence intervals (CIs) for computing indirect relationships. Furthermore, Shrout and Bolger (2002) established the appropriateness of bootstrapping procedure as it appears throughout its testing for the significance of indirect path relationships since its skewed distribution is distant from zero. Largely, the mediation testing was carried out after accomplishing a satisfactory fit with the 2,000 samples of bootstrapping according to the structural model estimation of indirect and direct effects amid the variables. The bias-corrected CIs were accounted at 95\% value (refer to Table 5).

Table 5. Mediation Results

\begin{tabular}{|l|l|l|l|l|l|c|}
\hline Hypothesized Relationships & $\begin{array}{l}\text { Direct } \\
\text { Effect }\end{array}$ & \multicolumn{2}{l|}{$\begin{array}{l}\text { Confidence } \\
\text { Interval }\end{array}$} & \multicolumn{2}{l|}{$\begin{array}{l}\text { Indirect } \\
\text { Effect } \\
\text { Through } \\
\text { Mediator }\end{array}$} & \multicolumn{2}{l|}{$\begin{array}{l}\text { Confidence } \\
\text { Interval }\end{array}$} \\
\hline & & $\begin{array}{l}\text { Lower } \\
\text { Limit }\end{array}$ & $\begin{array}{l}\text { Upper } \\
\text { Limit }\end{array}$ & & $\begin{array}{l}\text { Lower } \\
\text { Limit }\end{array}$ & $\begin{array}{l}\text { Upper } \\
\text { Limit }\end{array}$ \\
\hline H2a: PLB PQ-PLB-PV-PLB PI & .372 & .223 & .563 & .059 & .017 & .138 \\
\hline H3a: PLB PFuR-PLB PV-PLB PI & -.162 & -.286 & -.043 & -.055 & -.117 & -.019 \\
\hline H4a: PLB PFiR-PLB P-PLB PI & -.099 & -.180 & -.026 & -.023 & -.56 & -.003 \\
\hline H5a: PLB PSoR-PLBPV-PLB PI & -.200 & -.312 & -.086 & -.038 & -.091 & -.008 \\
\hline
\end{tabular}

Note: $\mathrm{PI}=$ purchase intention; $\mathrm{PV}=$ perceived value; $\mathrm{PQ}=$ perceived quality; $\mathrm{PFuR}$ = perceived functional risk; $\mathrm{PFiR}$ = perceived financial risk; $\mathrm{PSoR}=$ perceived social risk.

To test a hypothesis related to mediating relationships, we used a bootstrap method and for estimating the standard error of PLB perceived value mediator on all relationships among PLB perceived quality and PLB purchase intention. The indirect effects were significant, and 95\% CI does not include zero (lower bound = .223 and upper bound $=.563 ; p<.05$ ). The direct effects devoid of mediator were also significant and, after mediator was brought in, it indicated that PLB perceived value partially mediated the relationship between PLB perceived quality and PLB purchase intention, supporting hypothesis H2a. Similarly, for testing H3a, the bootstrapping results recommended that $95 \% \mathrm{CI}$ does not comprise zero for mediation relationships with PLB perceived functional risk, PLB perceived value, and PLB purchase intention. The indirect effect was significant, and 95\% CI does not include zero (lower bound $=-.286$ and upper bound $=-.043 ; p<.05$ ). The direct effects devoid of mediator were also significant and, while the mediator was brought in, it indicated that the PLB perceived value partially mediated the relation between PLB functional risk and PLB purchase intention, supporting hypothesis H3a.

Likewise, for testing $\mathrm{H}_{5}$ a, the bootstrapping results recommended that $95 \% \mathrm{CI}$ does not comprise zero for the mediation relationships among PLB perceived social risk, PLB perceived value, and PLB purchase intention. The indirect effect was significant, and 95\% CI does not include zero (lower bound $=-.312$ and upper bound $=$ -.086; $p<.05)$. The direct effect without mediator was also significant when the mediator was introduced, indicating that the PLB perceived value partially mediated the relation between PLB social risk and PLB purchase intention, supporting hypothesis $\mathrm{H}_{5} \mathrm{a}$. For testing $\mathrm{H}_{3} \mathrm{a}$, the bootstrapping results recommended that 95\% CI did not comprise zero for mediation relationships among PLB perceived functional risk, PLB perceived value, and PLB purchase intention. The indirect effect was significant, and 95\% CI did not include zero (lower bound $=-.286$ and upper bound $=-.043 ; p<.05$ ). The direct effects devoid of mediator are also significant and, after mediator was brought in, it indicated that the PLB perceived value partially mediated the relation among PLB functional risk and PLB purchase intention, supporting hypothesis H3a. 


\section{Discussion and Recommendations}

In the existing retail landscape, numerous imperatives to create, build, and manage successful PLBs have impelled retailers to devote a growing amount of resources to this endeavor. Considering the perceptions of consumers and their impact on buying decision processes is thus crucial for retail marketing and branding strategists. Furthermore, for driving consumer satisfaction, loyalty, and profitable PLBs, one of the significant tasks is to generate and communicate value to customers. To this conclusion, our study observed the causes that directly and indirectly influenced perceived value and, eventually, consumers' intent to purchase apparel PLBs. The purpose was to inspect the impact of the consumer's quality and risk perceptions on the purchase intention of apparel PLBs and to understand the mediating role of PLB perceived value. The responses collected from PLB consumers of department stores in India were analyzed using structural equation modeling. The results highlighted that consumers' buying intention of apparel PLBs was largely determined by PLB's perceived value for money, which echoes the study by Beneke and Carter (2015) that implied that perceived value had a strong and encouraging influence on the consumers' keenness to purchase PLBs. Retailers ought to consider clustering consumers either as per price or perceived quality to successfully target all segments with suitable strategies.

Moreover, all perceived risk dimensions, including functional, financial, and social risks, also positively influence PLB purchase intention. These results are in sync with the findings of Bhukya and Singh (2015). In addition, various relationships among the constructs of the study and mediating effects of PLB perceived value were examined. One central finding of our model showed that PLB perceived quality positively influenced PLB purchase intention and PLB perceived value mediated this association. The relationship between PLB perceived quality and PLB perceived value was, as anticipated, found to be positively significant, which is supported in marketing and retailing literature (Beneke et al., 2013; Cronin et al., 2000) and strongly recommends that retailing strategists need to keep investing in their PLB quality. The results further signaled that Indian consumers may perceive apparel PLBs on a similar foothold with their national counterparts in terms of their quality and the associated risks, provided retailers are offering value products to their consumers.

In addition, PLB perceived value partially mediated three more relationships: (1) PLB perceived functional risk on PLB purchase intention; (2) PLB perceived financial risk on PLB purchase intention; and (3) PLB perceived social risk on PLB purchase intention. Therefore, these results promote the conclusion that, in the case of apparel PLB products, PLB perceived value upholds their status as a critical intermediary component in the consumers' decision-making process while buying PLBs. Traditionally, with respect to quality or functional performances, PLBs were perceived as substandard to the manufacturer's brands (Richardson et al., 1996). PLB perceived functional risk shapes the negative attitude toward them (Semeijn et al., 2004), thus, diminishing the perceptions that the prices of manufacturer/national brands are unreasonable in comparison to private labels. Ural (2008) also revealed that high functional risk of the product affects consumer evaluations of PLB positively and consumers perceive the lack of symbolic quality of PLBs. However, Ural (2008) found that psychosocial risk associated with using a PLB product is not an important indicator of the consumer attitude toward the PLBs.

In addition, the findings showed that perceived high-quality variance within a product category is associated with a negative evaluation of PLB products in that category. Since grocery products are considered utilitarian, functional products with a sense of convenience are attached to them. Apparel products, however, are considered experiential, with a sense of symbolism and social risk attached to them (Vahie \& Paswan, 2006). Social risk is likely a perceived letdown of image/status through buying of a particular brand of clothing. For the apparel purchase, an Indian consumer seeks approval from their friends and family. Similarly, they compare apparel PLBs with self-image. However, Loebnitz et al. (2019) showed that national brands still have 
an edge over premium private labels, especially when consumers buy in a socially risky situation, as their expectations from national brands are higher.

Our research contributes to the existing literature and further deepens our understanding of PLB purchase behavior via a perceived value-based framework, which offers insights for retailers so that they can design suitable strategies to improve the PLB purchases among their target consumer groups. We recommend a few insights for retailers per our findings. To begin with, our study supports that perceived quality and perceived risks are significant cues that influence consumers' perceived value of PLBs and, eventually, willingness to purchase PLBs. It implies that retailers need to invest in improving perceived quality via leveraging PLB value to escalate sales. Retail store managers ought to also use other extrinsic cues to develop perceived quality of PLBs by attractive apparel patterns and striking designs and/or exhibiting PLB displays nearby leading national brands. Retailers need to vigorously reinforce perceived quality of PLBs at a strategic level. One suggested strategic tactic to enhance PLB perceived quality is to invest adequately in advertising. In addition, retailers can engage in building strong partnerships with their suppliers to augment the quality of ingredients of their product; in fact, Tsiotsou (2006) found that apparel quality may be improved by the use of quality stitches and superior workmanship. In addition, various retail store attributes maintain their critical significance in this setting. For instance, to disseminate communication and grow brand affinity, various social media platforms, particularly those that promote "word of mouth" and emphasize lower cost and higher impact, can be considered.

Second, it is of great importance that retail store managers need to recognize the degree to which PLB risks influence consumers' purchase intent of PLBs through the mediation effect of perceived value. Therefore, store retailers need to persuade consumers to experience and minimize their risks by informing consumers about PLBs. Consumer confidence can possibly be won by retailers by adopting various ways to minimize these perceived risks. For example, a retailer can promote and focus on the ingredient quality of products to lower perceived functional risk. Awareness of PLBs can also be enhanced by way of store promotions and conducting marketing communications frequently, such that consumers' awareness of PLBs is improved through their individual experiences or via word-of-mouth. Retail marketers may opt to promote PLBs in appropriate publications, including magazines and suitable web portals, which can instill a sense of enhanced quality as they perceive the merchandise. The retailer would be successful in diminishing consumer perceived financial risk when it positions PLBs on par with the national brands, especially in terms of price-quality linkages. In addition, consumers' financial risk minimization can also be achieved by practicing better exchange/return policies. To diminish perceived social risk, retailers need to enhance their reputation and store image, which can be achieved by practicing improved customer relationship management, superior service quality, and a pleasing store environment. In addition, retail service quality (for example, minimizing stock outages, ensuring courteous and friendly staff, guaranteeing a pleasing store atmosphere that is neat and clean, and optimizing the store design) maintenance can generate an optimistic halo effect for PLBs. Mitchell and Harris (2005) stated in their study that more psychosocial risk is felt by consumers if staff is unhelpful and discourteous, and customers may feel disregarded if the store reflects a noncaring attitude. Unfortunately, it may be that these aspects are often ignored in retail stores, which may result in tarnishing the image of their PLBs. Consequently, retailers are required to consider all these risks to build successful PLBs in the marketplace.

Third, retailers need to capitalize on the inter-relationships among quality, risks, and their clear and evident effects on value and purchase intention. Consequently, our study highlighted that customers' perceived product value was paramount in deciding to purchase PLBs. Our study implied that consciousness toward price and value has occurred because consumers are now seeing themselves as more intelligent and rational in making purchase decisions and seeking value-for-money offerings with a degree of quality. Retailers ought to think about segmenting their consumers either according to perceived quality or perceived social, financial, or functional risk, to successfully target all possible segments with suitable strategies. In addition, retailers can 
create value for customers by leveraging their own competencies, aligning what customers perceive to be valuable, and claiming differential benefits like a premium over the competitor's offerings. Though research strongly recommends the role of retailers as sellers and that of customers as buyers or users, nevertheless, with current digital platforms, customers and consumers co-create value by engaging in product innovation and product promotion through online blogs and forums to members and various communities. In fact, a profound understanding of varied determinants of consumer-perceived value might also assist retailers in applying consumer value management practices more comprehensively.

\section{Limitations and Future Research}

Our current research offers quite a few insights, but it also shows a few limitations. First, it considers only three determinants of purchase intention of PLBs; thus, future research must attempt to incorporate other determinants, such as familiarity and price, which could influence perceived value and, subsequently, purchase intention behavior. Second, the collected data are from a single city with convenience sampling; India displays a gigantic geographic area that has a spread of more than 25 states. Although efforts were made to acquire a true representative sample, a sample from varied states of India will facilitate much better and firmer results. Third, the relationships among the constructs of the study were tested by using a single product category, apparel, in department store retailing. The presence of PLBs is increasingly found in other retail formats like supermarkets, hypermarkets, etc., and in a range of product categories, including grocery, food, and personal care products. In India, this represents a very distinct market scenario; consequently, it will be useful to test the conceptual model of the study in various retail formats like hypermarkets, supermarkets, and in the context of other product categories. Furthermore, an attempt can be made to examine the variables in the context of luxury product categories. For further research endeavors, researchers can consider other individual factors that influence purchase decisions. To obtain robust results of examined relationships, an experimental study can be conducted wherein respondent's behavior can be manipulated. Finally, for valueconscious Indian consumers, retailers wishing to boost sales and increase consumer willingness to buy their PLBs ought to consider means to minimize customers' risk perceptions while increasing value for money. The store image may perhaps operate to ease the risk. Thus, our study provides apparent implications for apparel retailers to formulate an array of strategies for developing their PLBs. 


\section{References}

Aaker, D.A. (1991). Managing brand equity: Capitalizing on the value of brand name. The Free Press.

Agarwal, S., \& Teas, R.K. (2001). Perceived value: Mediating role of perceived risk. Journal of Marketing Theory and Practice 9(4), 1-14. https://doi.org/10.1080/10696679.2001.11501899

Alic, A., Agic, E., \& Pestek, A. (2013). Effects of risk-related purchasing factors on private label quality perceptions in Bosnia and Herzegovina. Challenges for the trade of Central and Southeast Europe 29, 137-154. https://doi.org/10.1108/S1876-066X(2013)oooo029012

Baltas, G. (1997). Determinants of store brand choice: A behavioral analysis. Journal of Product \& Brand Management, 6(5), 315-324. https://doi.org/10.1108/10610429710179480

Baltas, G., \& Argouslidis, P. C. (2007). Consumer characteristics and demand for store brands. International Journal of Retail \& Distribution Management, 35(5), 328-341. https://doi.org/10.1108/09590550710743708

Bauer, R.A., (1960). Consumer behavior as risk taking. In Hancock, R. S. (Ed.), Dynamic marketing for a changing world. American Marketing Association (pp. 389-398.

Beneke, J., \& Carter, S. (2015). The development of a consumer value proposition of private label brands and the application thereof in a South African retail context. Journal of Retailing and Consumer Services, 25, 22-35. https://doi.org/10.1016/j.jretconser.2015.03.002

Beneke, J., Flynn, R., Greig, T., \& Mukaiwa, M. (2013). The influence of perceived product quality, relative price and risk on customer perceived value and willingness to buy: A study of private label merchandise. Journal of Product \& Brand Management, 22(3), 218-228.

https://doi.org/10.1108/JPBM-02-2013-0262

Beneke, J., Greene, A., Lok, I., \& Mallett, K. (2012). The influence of perceived risk on purchase intent-The case of premium grocery private label brands in South Africa. Journal of Product \& Brand Management, 21(1), 4-14.

Bhukya, R., \& Singh, S. (2015). The effect of perceived risk dimensions on purchase intention: An empirical evidence from Indian private labels market. American Journal of Business, 3o(4), 218-230. https://doi.org/10.1108/AJB-10-2014-0055

Broydrick, S. C. (1998). The 7 universal laws of customer value: How to win customers and influence markets. McGraw-Hill.

Chakravarti, A., \& Janiszewski, C. (2003). The influence of macro-level motives on consideration set composition in novel purchase situations. Journal of Consumer Research, 3O(2), 244-258. https://doi.org/10.1086/376803

Cronin, J. J., Jr., Brady, M. K., \& Hult, G. T. M. (2000). Assessing the effect of quality, value, and customer satisfaction on consumer behavioral intentions in service environments. Journal of Retailing, 76(2), 193-218. https://doi.org/10.1016/Soo22-4359(00)0o028-2

Diallo, M. F. (2012). Effects of store image and store brand price-image on store brand purchase intention: Application to an emerging market. Journal of Retailing and Consumer Services, 19(3), 360-367. https://doi.org/10.1016/j.jretconser.2012.03.010

Diallo, M. F., Chandon, J.-L., Cliquet, J., \& Phillippe, J. (2013). Factors influencing consumer behaviour towards store brands: Evidence from the French market. International Journal of Retail \& Distribution Management, 41(6), 422-441. https://doi.org/10.1108/09590551311330816 
Dodds, W. B., Kent, B. M., \& Grewal, D. (1991). Effects of price, brand, and store information on buyers' product evaluations. Journal of Marketing Research, 28(3), 307-319. https://doi.org/10.1177/002224379102800305

Dowling, G. R., \& Staelin, R. (1994). A model of perceived risk and intended risk-handling activities. Journal of Consumer Research, 21(1), 119-134. http://dx.doi.org/10.1086/209386

Glynn, M., \& Widjaja, T. (2015). Private label personality: Applying brand personality to private label brands. The International Review of Retail, Distribution and Consumer Research (25), 17-25. https://doi.org/10.1080/09593969.2015.1017772

Gonzalez Mieres, C., Diaz Martin, A. M. \& Trespalacios Gutierrez, J. A. (2006). Antecedents of the difference in perceived risk between store brands and national brands. European Journal of Marketing, 40 (1/2), 61-82. https://doi.org/10.1108/03090560610637310

Graf, A., \& Maas, P. (2008). Customer value from a customer perspective: A comprehensive review. Journal of Betriebswirtschaft, 58, 1-20. https://doi.org/10.1007/s11301-008-0032-8

Grewal, D., Krishnan, R., Baker, J., \& Borin, N. (1998). The effect of store name, brand name and price discounts on consumers' evaluations and purchase intentions. Journal of Retailing, 74(3), 331-352. https://doi.org/10.1016/Soo22-4359(99)80099-2

Hair, J. F., Jr., Black, W. C., Babin, B. J., \& Anderson, R. E. (2013). Multivariate data analysis (7th ed.). Pearson Higher Education.

Hansen, H., Samuelsen, B. M., \& Silseth, P.R. (2008). Customer perceived value in B-t-B service relationships: Investigating the importance of corporate reputation. Industrial Marketing Management, 37(2), 206-217. https://doi.org/10.1016/j.indmarman.2006.09.001

Herstein R., Drori, N., Berger, R., \& Barnes, B. R. (2017). Exploring the gap between policy and practice in private branding strategy management in an emerging market. International Marketing Review, 34(4), 559-578. https://doi.org/10.1108/IMR-05-2014-0188

Hoch, S. J. (1996). How should national brands think about private labels? Sloan Management Review, 37(2), 89-102.

Hsin Chang, H., \& Wang, H.-W. (2011). The moderating effect of customer perceived value on online shopping behaviour. Online Information Review, 35(3), 333-359. https://doi.org/10.1108/14684521111151414

Huei Cham, T., Kar Yan Ng, C., Mee Lim, Y., \& Chang, B. L. (2018). Factors influencing clothing interest and purchase intention: A study of Generation Y consumers in Malaysia. The International Review of Retail, Distribution and Consumer Research, 28(2), 174-189. https://doi.org/10.1080/09593969.2017.1397045

Jacoby, J., \& Kaplan, L. B. (1972). The components of perceived risk. In M. Venkatesan (Ed.). Proceedings of the Third Annual Conference of the Association for Consumer Research (pp. 382-393). Association for Consumer Research.

Jin, B., \& Gu Suh, Y. (2005). Integrating effect of consumer perception factors in predicting private brand purchase in a Korean discount store context. Journal of Consumer Marketing, 22(2), 62-71. https://doi.org/10.1108/07363760510589226

Kara, A., Rojas-Méndez, J.I., Kucukemiroglu, O., \& Harcar, T. (2009). Consumer preferences of store brands: Role of prior experiences and value consciousness. Journal of Targeting, Measurement and Analysis for Marketing, 17(2), 127-137. https://doi.org/10.1057/jt.2009.6

Kline, R. B. (2005). Principles and practice of structural equation modeling (2nd ed.). Guilford Press. 
Konuk, F. A. (2018). The role of store image, perceived quality, trust and perceived value in predicting consumers' purchase intentions towards organic private label food. Journal of Retailing \& Consumer Services, 43, 304-310. https://doi.org/10.1016/j.jretconser.2018.04.011

Lapierre, J. (2000). Customer-perceived value in industrial contexts. Journal of Business Industrial Marketing, 15(2/3), 122-145. https://doi.org/10.1108/08858620010316831

Liljander, V., Polsa, P., \& van Riel, A. (2009). Modelling consumer responses to an apparel store brand: Store image as a risk reducer. Journal of Retailing and Consumer Services, 16(4), 281-290. https://doi.org/10.1016/j.jretconser.2009.02.005

Loebnitz, N., Zielke, S., \& Grunert, K. G. (2019). The moderating impact of social risk, shame, and guilt on purchase intentions of premium private labels at food discounters. British Food Journal, 121(11), 2651-2665. https://doi.org/10.1108/BFJ-02-2019-0114

Manikandan, M. K. M. (2020). Store brand and perceived risk on private label brand attitude. Journal of Indian Business Research, 12(1): 133-150. https://doi.org/10.1108/JIBR-09-2019-0280

Mitchell, V.W., \& Harris, G. (2005). The importance of consumers' perceived risk in retail strategy. European Journal of Marketing, 39(7/8), 821-837. https://doi.org/10.1108/03090560510601789

Muruganantham, G., \& Priyadharshini, K. (2017). Antecedents and consequences of private brand purchase: A systematic review and a conceptual framework. International Journal of Retail \& Distribution Management, 45(6), 660-682. https://doi.org/10.1108/IJRDM-02-2016-0025

Nenycz-Thiel, M., \& Romaniuk, J. (2012). Value-for-money perceptions of supermarket and private labels. Australasian Marketing Journal, 2O(2), 171-177. https://doi.org/10.1016/j.ausmj.2011.12.002

Oliver, R. L. (2010). Satisfaction: A behavioral perspective on the consumer (2nd ed.). Routledge. https://doi.org/10.4324/9781315700892

Preacher, K. J., \& Hayes, A. F. (2008). Asymptomatic and resampling strategies for assessing and comparing indirect effects in multiple mediator models. Behavior Research Methods, 4O(3), 879-891. https://doi.org/10.3758/brm.40.3.879

Retnawati, B. B., Ardyan, E., \& Farida, N. (2018). The important role of consumer conviction value in improving intention to buy private label product in Indonesia. Asia Pacific Management Review, 23(3), 193-200. https://doi.org/10.1016/j.apmrv.2017.07.003

Richardson, P. S., Jain, A. K., \& Dick, A. (1996). Household store brand proneness: A framework. Journal of Retailing, 72(2), 159-185. https://doi.org/10.1016/Soo22-4359(96)90012-3

Schiffman, L. G., \& Kanuk L. L. (eds.). (2011). Consumer behavior (10th ed.). Pearson.

Semeijn, J., Van Riel, A. C. R., \& Ambrosini, A. B. (2004). Consumer evaluations of store brands: Effects of store image and product attributes. Journal of Retailing and Consumer Services, 11(4), 247-258. https://doi.org/10.1016/So969-6989(03)o0051-1

Shrout, P. E., \& Bolger, N. (2002). Mediation in experimental and nonexperimental studies: New procedures and recommendations. Psychological Methods, 7(4), 422-445.

Sirohi, N., McLaughlin, E. W., \& Wittink, D.R. (1998). A model of consumer perceptions and intentions for a supermarket retailer. Journal of Retailing, 74(2), 223-245. https://doi.org/10.1016/so0224359(99)80094-3

Stone, R. N., \& Grønhaug, K., K. (1993). Perceived risk: Further considerations for the marketing discipline. European Journal of Marketing, 27(3): 39-50. http://dx.doi.org/10.1108/03090569310026637 
Swait, J., \& Sweeney, J. C. (2000). Perceived value and its impact on choice behavior in a retail setting. Journal of Retailing and Consumer Services, 7, 77-88. https://doi.org/10.1016/So9696989(99)00012-0

Sweeney, J. S., \& Soutar, G. N. (2001). Consumer perceived value: The development of a multiple item scale. Journal of Retailing, 77(2), 203-220.

Sweeney, J. C., Soutar, G. N., \& Johnson, L.W. (1999). The role of perceived risk in the quality-value relationship: A study in a retail environment. Journal of Retailing, 75(1), 77-105. https://doi.org/10.1016/Soo22-4359(99)80005-0

Thanasuta, K. (2015). Thai consumers' purchase decisions and private label brands. International Journal of Emerging Markets, 1O(1), 102-121. https://doi.org/10.1108/IJOEM-02-2011-0016

Tsiotsou, R. (2006). The role of perceived product quality and overall satisfaction on purchase intentions. International Journal of Consumer Studies, 3o(2), 207-217. https://doi.org/10.1111/j.14706431.2005.00477.x

Ural, T. (2008). Factors affecting the success of store brands in Turkish retailing market. Innovative Marketing, 4(2), 33-41.

Vahie, A., \& Paswan, A. K. (2006). Private label brand image: Its relationship with store image and national brand. International Journal of Retail \& Distribution Management, 34(1), 67-84. https://doi.org/10.1108/09590550610642828

Veloutsou, C., Gioulistanis, E., \& Moutinho, L. (2004). Own labels choice criteria and perceived characteristics in Greece and Scotland: Factors influencing the willingness to buy. Journal of Product \& Brand Management, 13(4), 228-241. https://doi.org/10.1108/10610420410546943

Woodall, T. (2003). Conceptualising "value for the customer:" An attributional, structural and dispositional analysis. Academy of Marketing Science Review, 2003, 1-42. https://doi.org/10.1016/j.ausmj.2010.11.001

Wu, P. C. S., Yeh, G. Y.-Y., \& Hsiao, C.-R. (2011). The effect of store image and service quality on brand image and purchase intention for private label brands. Australian Marketing Journal, 19(1), 30-39. https://doi.org/10.1016/j.ausmj.2010.11.001

Yang, D., \& Wang, X. (2010). The effect of 2-tier store brands' perceived quality, perceived value, brand knowledge and attitude on store loyalty. Frontiers of Business Research in China, 4(1), 1-28. https://doi.org/10.1007/s11782-010-0001-7

Yan, L., Xiaojun, F., Li, J., \& Dong, X. (2019). Extrinsic cues, perceived quality, and purchase intention for private labels: Evidence from the Chinese market. Asia Pacific Journal of Marketing and Logistics, 31(3), 2019, 714-727. https://doi.org/10.1108/APJML-08-2017-0176

Yee, C. J., \& San, N. C. (2011). Consumers' perceived quality, perceived value and perceived risk towards purchase decision on automobile. American Journal of Economics and Business Administration, 3(1), 47-57. https://doi.org/10.3844/ajebasp.2011.47.57

Zeithaml, V.A. (1988). Consumer perceptions of price, quality, and value: A means-end model and synthesis of evidence. Journal of Marketing, 52(3), 2-22. https://doi.org/10.2307/1251446

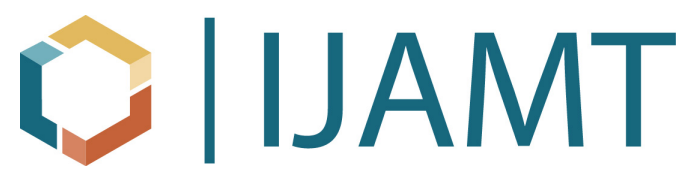

The International Journal of Applied Management and Technology (IJAMT), sponsored by Walden University's College of Management and Technology, is a peer-reviewed, online journal that addresses contemporary national and international issues related to management and technology. 